\title{
Effect of Nicotine-free Tobacco Extract on DNA Damage Responses in Cancerous and Non-cancerous Cells
}

\section{Ying Yu ${ }^{1,2}$, Pavan K Soma ${ }^{1}$, Y Martin Lo ${ }^{1}$, Cheng-I Wei ${ }^{1}$ and Wen-Hsing Cheng ${ }^{1 *}$}

${ }^{1}$ Department of Nutrition and Food Science, University of Maryland, College Park, MD, 20742, USA

${ }^{2}$ College of Life Sciences, Northwest A \& F University, Yangling, Shannxi, 712100, China

\begin{abstract}
The use of cigarette products tags tobacco as a crop with serious health concerns, but nutraceutical potentials of tobacco constituents other than nicotine have not been adequately explored. The objective of this study was to investigate the effect of nicotine-free tobacco extract on the activation of tumorigenesis barriers. Four lines of human cells were treated with a nicotine-free tobacco extract $(0.1$ and $1 \mathrm{mg} / \mathrm{mL}, 0-48 \mathrm{~h})$. MRC-5 and CCD841 non-cancerous cells treated with the tobacco extract showed hypersensitivity, apoptosis and cell cycle arrest in $S$ and $G_{2} / M_{\text {phases, }}$ and induction of DNA damage response as evidenced by phosphorylation of ataxia telangiectasia mutated at Ser1981 and histone H2A.X at Ser-139. In contrast, HCT 116 cancerous cells, with or without functional DNA mismatch repair, were resistant to the tobacco extract treatment. These results suggest that tobacco components other than nicotine may have a chemoprevention potential that stifles tumorigenesis at the early stage of tumorigenesis.
\end{abstract}

Keywords: Tobacco; Nicotine; Cancer; DNA damage

Abbreviations: ATM: Ataxia Telangiectasia Mutated; PBS: Phosphate-Buffered Saline; hMLH1: MutL Homolog 1; MTT: 3-[4,5-Dimethylthiazol-2-yl]-2,5-diphenyltetrazolium bromide; pATM Ser1981: phospho-ATM at Ser-1981; $\gamma$ H2AX: phospho H2A.X at Ser-139

\section{Background}

Tobacco (Nicotiana tabacum L.) has been grown primarily for commercial production of cigarettes and related products with a long history. Due to health concerns and government regulations in the last 20 years, tobacco production has been declining. Irrespective of smoking uses, tobacco is in fact a good source of biomass with superior protein quality and nutrition value [1,2]. Tobacco contains thousands of chemicals and proteins with various characteristics [3]. Along the same line, recent applications of alternative uses of tobacco have engineered to yield a number of recombinant proteins with therapeutic potentials including hormones, growth factors, hair growth, and vaccine antigens [4-7]. Moreover, tobacco can grow in high density and produce more than four-fold proteins than soybeans do, providing an excellent source for crude protein extract.

Cancer chemoprevention suppresses or prevents the initial phase of tumorigenesis or the progression of neoplasm to cancer. Genome maintenance is an ideal target for chemoprevention. Recent advances suggest that ataxia telangiectasia mutated (ATM)-dependent DNA damage response serves as a major barrier of human tumorigenesis at the early stage [8-10]. Heritable mutations in ATM cause ataxiatelangiectasia, a genome instability syndrome characterized by cancer predisposition, neurodegeneration, and premature aging. In response to DNA damage, the ATM kinase is rapidly activated and mediates multiple downstream pathways, resulting in DNA damage checkpoint activation and repair. H2A.X is a phosphorylation substrate of ATM and a reliable marker of DNA breaks [11]. Furthermore, many cases of colorectal cancers are characterized by microsatellite instability due to a defective mismatch repair system [12]. Human MutL homologue-1 (hMLH1) is an important DNA mismatch repair protein that forms a complex with post-meiotic segregation protein-2 to recognize and stabilize mismatched DNA. Whereas somatic mutations in mismatch repair genes and epigenetic silencing of $h M L H 1$ expression are observed in a significant portion of sporadic colorectal cancers, germline mutations in $h M L H 1$ account for the majority of autosomal dominant non-polyposis colon cancer $[13,14]$.

In addition to the well-characterized nicotine, tobacco contains many unknown chemicals, some of which may be of medicinal applications. A tobacco extract has been shown to induce apoptosis in oral squamous carcinoma cells [15]. Interestingly, an optimal phosphate buffer system can effectively remove nicotine residuals and recover proteins from tobacco leaves up to $94.5 \%$ [2]. In the current study, we proposed that the nicotine-free tobacco extract can intervene tumorigenesis by targeting the DNA damage response pathway. To test this hypothesis, we employed the nicotine-free tobacco extract isolated by an effective and scalable system with an aim to avoid the confounding effect of nicotine on tumorigenesis.

\section{Methods}

\section{Cell culture and chemicals}

The MRC-5 human normal lung fibroblasts and CCD841 CoN human normal colorectal epithelial cells were cultured in minimum Eagle's medium (Mediatech, Herndon, VA) supplemented with 15\% fetal bovine serum (Sigma-Aldrich, St. Louis, MO), essential amino acids $(1 \mathrm{ng} / \mathrm{mL})$, nonessential amino acids $(1 \mathrm{ng} / \mathrm{mL})$, vitamins $(1 \mathrm{ng} /$ $\mathrm{mL})$, penicillin $(50 \mathrm{IU} / \mathrm{mL})$, and streptomycin $(50 \mu \mathrm{g} / \mathrm{mL})$ at $37^{\circ} \mathrm{C}$ in a $5 \% \mathrm{CO} 2$ incubator. HCT 116 human colorectal adenocarcinoma cells complemented with an empty vector or a hMLH1-expressing vector

*Corresponding author: Wen-Hsing Cheng, Department of Nutrition and Food Science, University of Maryland, 0112 Skinner Building, College Park, MD 20742, USA, Tel: +1-301-405-2940; Fax: +1-301-314-3313; E-mail: whcheng@umd.edu

Received February 02, 2012; Accepted February 24, 2012; Published February 28, 2012

Citation: Yu Y, Soma PK, Lo YM, Wei CL, Cheng WH (2012) Effect of Nicotine-free Tobacco Extract on DNA Damage Responses in Cancerous and Non-cancerous Cells. J Carcinogene Mutagene S3:002. doi:10.4172/2157-2518.S3-002

Copyright: (c) 2012 Yu Y, et al. This is an open-access article distributed unde the terms of the Creative Commons Attribution License, which permits unrestricted use, distribution, and reproduction in any medium, provided the original author and source are credited. 
(HCT 116+hMLH1) were maintained in Dulbecco's modified Eagle's medium (Mediatech) supplemented with $10 \%$ fetal bovine serum, penicillin $(50 \mathrm{IU} / \mathrm{mL})$, and streptomycin $(50 \mu \mathrm{g} / \mathrm{mL})$ [16]. This isogenic pair of HCT116 cell lines was kindly provided by Dr. Francoise Praz (Centre National de la Recherche Scientifique, Villejuif, France.) [17].

The nicotine-free tobacco extract used in this study was prepared form low alkaloid tobacco (N. tabacum L. cv. MD-609LA) using the $\mathrm{Na}_{2} \mathrm{HPO}_{4}-\mathrm{KH}_{2} \mathrm{PO}_{4}$ buffer system as described previously [2]. The nicotine was completely removed from the protein and undetectable in the extract [2]. The extract powder was mixed with phosphate buffered saline (PBS) and placed on a shaker at $50 \mathrm{rpm}$ for $1 \mathrm{~h}$ at room temperature, followed by filtration through a $0.22 \mu \mathrm{m}$ filter. 3-[4,5-Dimethylthiazol-2-yl]-2,5-diphenyltetrazolium bromide (MTT, Calbiochem, La Jolla, CA) was dissolved in PBS.

\section{Cell viability assay}

Cell viability assay was performed as described previously with modifications [18]. Briefly, cells were seeded in 24-well plates $\left(1 \times 10^{4}\right.$ cells/well) and treated with the tobacco extract at a final concentration of 0.1 or $1 \mathrm{mg} / \mathrm{mL}$ for 3 days. The medium was then refreshed and incubated with MTT $(0.5 \mathrm{mg} / \mathrm{mL})$ at $37^{\circ} \mathrm{C}$ for $4 \mathrm{~h}$. DMSO was then added to dissolve formazan, followed by spectrophotometric quantification at 595 nm (FLUOstar OPTIMA, BMG Labtech, Cary, NC, USA). Percent viability was calculated as: [optical density of treated sample/optical density of untreated cells] $\times 100 \%$.

\section{Flow cytometric measurement of apoptosis}

Cells were plated $\left(5 \times 10^{4}\right.$ cells $/ 3.5-\mathrm{cm}^{2}$ dish $)$ and grown to $70 \%$ confluency and treated with the tobacco extract $(1 \mathrm{mg} / \mathrm{mL})$ for 24 or $48 \mathrm{~h}$, followed by trypsin treatment for $5 \mathrm{~min}$ at $37^{\circ} \mathrm{C}$. The cells were collected and spun down at $500 \times \mathrm{g}$ for $5 \mathrm{~min}$. The pellets were resuspended in a buffer $(500 \mu \mathrm{L})$ containing $5 \mu \mathrm{L}$ Annexin V-FITC and $1 \mu \mathrm{L}$ SYTOX green dye and incubated at room temperature in dark for 5 min (Biovision Annexin V-FITC Apoptosis Detection, K201400). Apoptotic cells were then analyzed by the detection of cell surface Annexin V-FITC (Ex, $488 \mathrm{~nm}$; Em, $530 \mathrm{~nm}$ ) using a BD FACSCanto II flow cytometer.

\section{Cell cycle analyses}

Cell cycle analysis was performed as described previously [16] with modifications. Briefly, cells were seeded $\left(5 \times 10^{4}\right.$ cells $)$ into $3.5-\mathrm{cm}^{2}$ dishes and treated with the nicotine-free tobacco extract $(1 \mathrm{mg} / \mathrm{mL})$ for 0-48 h. Trypsinized, single cells were then incubated with Vybrant DyeCycleTM Violet stain (Invitrogen, $5 \mu \mathrm{M}$ ) at $37^{\circ} \mathrm{C}$ for $30 \mathrm{~min}$ in dark. Vybrant DyeCycle Violet is DNA-selective and cell membranepermeable and is responsive to laser light for DNA content analysis in living cells. Cell cycle profiles were analyzed (Ex, $405 \mathrm{~nm}$; Em, $440 \mathrm{~nm}$ ) using a BD FACSCanto II flow cytometer.

\section{Immunofluorescence analyses}

Immunofluorescent analyses of phospho-H2A.X at Ser-139 $(\gamma$ H2A.X) and phospho-ATM at Ser-1981 (pATM Ser-1981) were performed as described previously [19]. Briefly, cells $\left(2 \times 10^{4}\right.$ cells $)$ were grown on coverslips in $3.5-\mathrm{cm}^{2}$ dishes and incubated with the nicotine-free tobacco extract for 0-48 h. The cells were washed in PBS, fixed in $4 \%$ paraformaldehyde (in PBS) for 15 min and then in $90 \%$ cold methanol for $10 \mathrm{~min}$, permeabilized in $0.3 \%$ Triton-X 100 at room temperature for $10 \mathrm{~min}$, and incubated overnight with the following antibodies at $4^{\circ} \mathrm{C}$ : H2A.X (1:500, Abcam, Cambridge, MA), $\gamma \mathrm{H} 2 \mathrm{~A} . \mathrm{X}$ (1:500, Abcam), ATM (1:500, Epitomics, Burlingame, CA) and pATM Ser-1981 (1:500, Rockland, Gilbertsville, PA). The immunostaining signals were determined by a flurorescence microscope (AxioObserver 100, Carl Zeiss, Oberkochen, Germany), followed by deconvolution with the Axion Vision Release 4.7.2.0 software fordata analysis.

\section{Statistics analysis}

All data were analyzed using the GraphPad Prism 5.0 software (GraphPad Software, Inc., La Jolla, CA). Student's t-test was applied to determine statistical significance between the treatments and the control.

\section{Results and Discussion}

\section{Effect of nicotine-free tobacco extract on cell proliferation}

A previous report showed that a nicotine-containing tobacco extract induces cancer cell death [15]. Here, results from cell sensitivity assay showed that HCT 116 cancerous cells (Figure 1) were resistant to the nicotine-free tobacco extract $(1 \mathrm{mg} / \mathrm{mL})$ whereas the treatment reduced $(p<0.05)$ the viability of HCT $116+$ hMLH1, MRC- 5 and CCD 841 (Figure 1) cells by $32 \%, 42 \%$ and $81 \%$, respectively. The nicotine-free tobacco extract did not affect the viability of the four cell lines when treated at a concentration of $0.1 \mathrm{mg} / \mathrm{mL}$. These results indicate that bioactive components other than nicotine in tobacco leaves exhibited cytotoxic effect, the extent of which was greater in non-cancerous and DNA mismatch repair proficient HCT 116 cells, as compared to the DNA mismatch repair deficient HCT 116 cells.

Induction of apoptosis by nicotine-free tobacco extract in non-cancerous, but not in the cancerous HCT 116 cells

Apoptosis is a form of programmed cell death, which is typically hampered during the course of tumorigenesis. Annexin V externalization is an event occurred at the early stage of apoptosis development. Results from flow cytometric analyses indicated that HCT 116 and HCT 116+hMLH1 cancerous cells (Figure 2) did not show induction of Annexin $\mathrm{V}$ expression after treatment with the tobacco extract. In contrast, MRC-5 and CCD841 non-cancerous cells showed significant induction of Annexin $\mathrm{V}$ expression, and the onset of which is earlier in CCD841 than in MRC-5 cells (Figure 2).

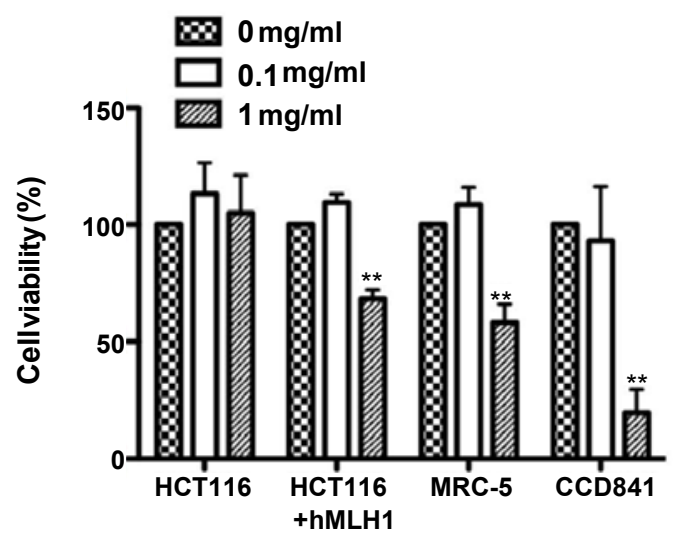

Figure 1: Effects of nicotine-free tobacco extract on cell viability. Cells were treated with nicotine-free tobacco extract for 2 days, followed by a MTT assay to estimate for cell viability. Values are means \pm SEM, $n=3 .{ }^{* *}, p<0.01$, compared with cells without tobacco treatment. 
Nicotine-free tobacco extract differentially induces cell cycle arrest in the cells

We further investigated whether or not the tobacco extract treatment impacted on cell cycle distribution. Analyses of flow cytometric results showed that HCT 116+hMLH1 cells arrested in S phase at $24 \mathrm{~h}$ and G0/G1 phase at $48 \mathrm{~h}$ after treatment with the nicotine-free tobacco extract, whereas the cell cycle distribution in HCT 116 cells did not significantly change after the treatment (Figure 3). In MRC-5 cells, the treatment resulted in increased G2/M cells at $48 \mathrm{~h}$ and $\mathrm{S}$ phase cells at $24 \mathrm{~h}$ and G2/M cells at $48 \mathrm{~h}$ (Figure 3). CCD841 cells endogenously showed greater $\mathrm{S}$ and G2/M cells as compared to HCT116 and MRC-5 cells. After treatment with the tobacco extract, there was an increase in G0/G1 cells and a decrease in G2/M cells at 24 and 48 h (Figure 3).

Nicotine-free tobacco extract induces the formation of pATM Ser-1981 and $\gamma \mathrm{H} 2 \mathrm{~A}$.X in non-cancerous, but not in cancerous cells

To determine whether or not the nicotine-free tobacco extract activates DNA damage responses, we determined nuclear expression of $\gamma$ H2A.X (a marker of DNA breaks) and pATM Ser-1981 (a marker of

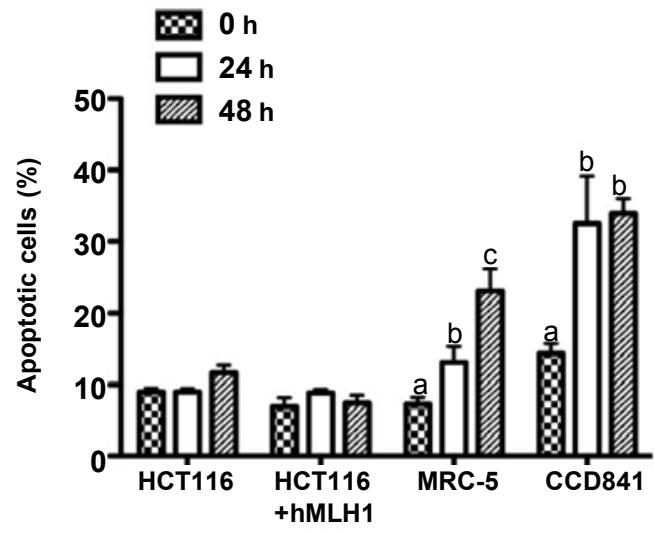

Figure 2: Effects of nicotine-free tobacco extract $(1 \mathrm{mg} / \mathrm{mL})$ on apoptosis in the cells. Apoptotic cells were estimated by Annexin V-expressing cells using flow cytometry. Values are means $\pm \operatorname{SEM}, n=3$. Bars without sharing a common letter are different $(p<0.05)$

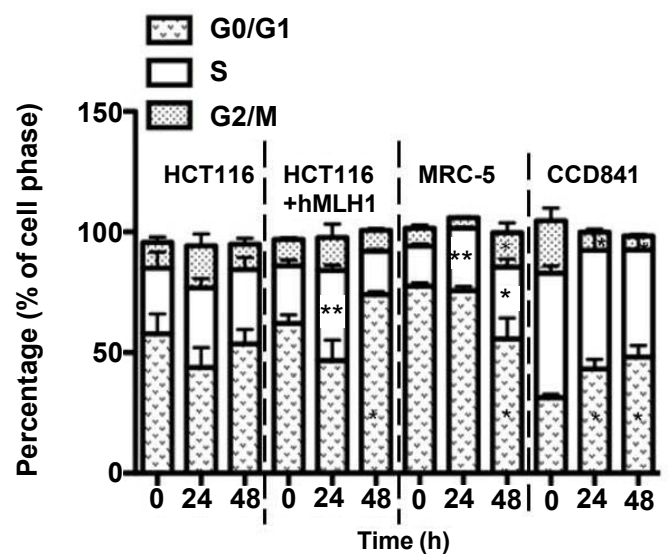

Figure 3: Effect of nicotine-free tobacco extract $(1 \mathrm{mg} / \mathrm{mL})$ on cell cycle distribution. At the indicated time points, harvested cells were stained with DyeCycle ${ }^{\circledR}$ Violet and cell cycle distribution was analyzed by flow cytometry. Values are means \pm SEM $, n=3 .{ }^{*}, p<0.05 ;{ }^{* *}, p<0.01$, compared with $0 \mathrm{~h}$.

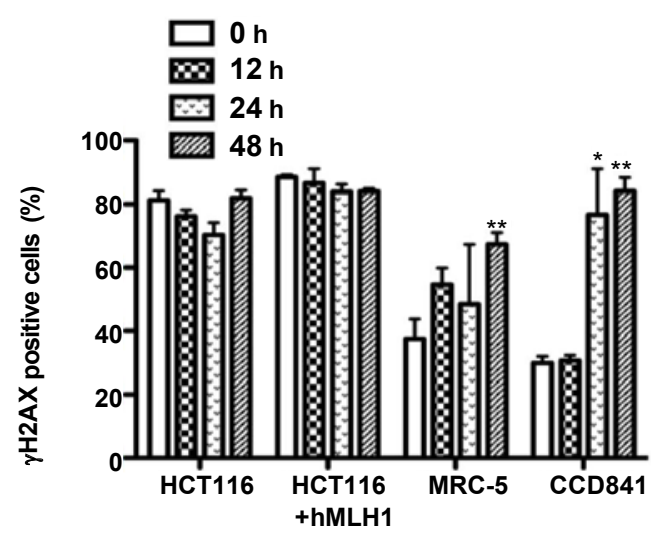

Figure 4: Effect of nicotine-free tobacco extract $(1 \mathrm{mg} / \mathrm{mL})$ on $\mathrm{YH} 2 \mathrm{~A} . \mathrm{X}$ focus formation in the nucleus. At the indicated time points, cells were collected for immunofluorescence analyses of $\mathrm{YH} 2 \mathrm{~A}$.X foci. A nucleus containing more than five foci is defined as a focus-positive cell. Values are means $\pm \operatorname{SEM}, n=3$. ${ }^{*}, p$ $<0.05 ;{ }^{* *}, \mathrm{p}<0.01$, compared to $0 \mathrm{~h}$.

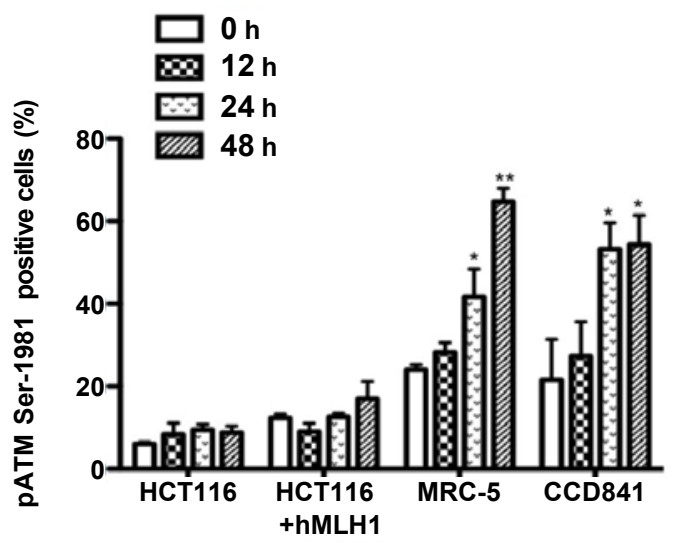

Figure 5: Effect of nicotine-free tobacco extract $(1 \mathrm{mg} / \mathrm{mL})$ on pATM Ser-1981 focus formation in the nucleus. At the indicated time points, cells were collected for immunofluorescence analyses of pATM Ser-1981. A nucleus containing more than five foci is defined as a focus-positive cell. Values are means $\pm S E M$, $n=3 .{ }^{*}, p<0.05 ;{ }^{*}, \mathrm{p}<0.01$, compared to $0 \mathrm{~h}$.

ATM pathway activation). Results from immunofluorescent analyses demonstrated that treatment with nicotine-free tobacco extract $(0.1$ $\mathrm{mg} / \mathrm{mL}$ ) resulted in a time-dependent induction of $\gamma \mathrm{H} 2 \mathrm{~A} . \mathrm{X}$ (Figure 4 and Supplemental Figure 1) and pATM Ser-1981 in MRC-5 and CCD841 (Figure 5 and Supplemental Figure 2) non-cancerous cells. In contrast, the treatment did not noticeably induce $\gamma \mathrm{H} 2 \mathrm{~A} . \mathrm{X}$ (Figure 4) and pATM Ser-1981 focus formation in HCT 116 or HCT $116+$ hMLH1 (Figure 5) cancerous cells. Taken together, the tobacco extract induces DNA breaks and ATM pathway activation in the MRC-5 and CCD841 non-cancerous but not in HCT 116 and HCT $116+$ hMLH1 cancerous cells.

\section{Discussion and Perspectives}

Activation of DNA damage response is known as an early barrier of tumorigenesis $[8,9]$. Here we report that the nicotine-free tobacco extract can activate DNA damage responses in non-cancerous but not in cancerous cells, suggesting a potentially promising application for this ill-imaged crop. 
Citation: Yu Y, Soma PK, Lo YM, Wei CL, Cheng WH (2012) Effect of Nicotine-free Tobacco Extract on DNA Damage Responses in Cancerous and Non-cancerous Cells. J Carcinogene Mutagene S3:002. doi:10.4172/2157-2518.S3-002

Previous study in our laboratory demonstrates that selenium compounds can activate an ATM-dependent DNA damage response in noncancerous but not in cancerous cells [19]. Apparently, chemicals other than nicotine in tobacco leaves may similarly elicit ATM pathway induction. Indeed, ATM is activated by various forms of cellular stress, including reactive oxygen species, DNA damage and chromatin remodelling. The nicotine-free tobacco extract induces ATM pathway activation, $\gamma \mathrm{H} 2 \mathrm{~A}$.X formation, and apoptosis in noncancerous but not in cancerous cells, suggesting that the tobacco extract can target the ATM pathway for activation of early tumorigenesis barriers. One future direction is to identify the bioactive components in the tobacco extract, among the five thousand chemicals known to exist in tobacco leaves [20], which exhibit chemoprevention effect.

Although both HCT 116 and HCT $116+$ hMLH1 cancerous cells are resistant to apoptosis induction by the nicotine-free tobacco extract, the latter cells are sensitive to the tobacco extract treatment in a dose-dependent manner. Therefore, induction of apoptosis may not account for cellular sensitivity to the nicotine-free tobacco extract in cancerous cells. These results also suggest that the tobacco extract does not sensitize HCT $116+$ hMLH1 cells to cell death by coupling DNA mismatch repair to apoptosis. In contrast, treatment of MRC-5 and CCD841 noncancerous with the tobacco extract comparably induces cell death and apoptosis. Therefore, the nicotine-free tobacco extract may sensitize non-cancerous and cancerous cells through distinct stress response pathways.

Treatment with the tobacco extract impacts cell cycle profiles in HCT 116 + hMLH1, MRC-5 and CCD841 cells; however, the changes are not associated with viability of the cells after the tobacco extract treatment. Nonetheless, HCT 116 cells are resistant to treatment with the tobacco extract and the cell cycle profile does not significantly change after the treatment. Cell cycle arrest is known as a cellular defence mechanism that allows for DNA repair and apoptosis events to occur. Thus, these results suggest that the tobacco extract differentially elicits cell cycle checkpoint responses, but the patterns of changes are not associated with cell sensitivity to the tobacco extract.

Cancer cells are known to carry increased genome instability and are refractory to treatment with DNA-damaging agents such as selenium compounds [19]. Similarly, HCT $116+$ hMLH1 cells are more sensitive than the DNA mismatch repair deficient HCT 116 cells to treatment with selenium compounds [16]. This may explain why the DNA mismatch repairs proficient HCT $116+$ hMLH1 and noncancerous cells are more sensitive to the nicotine-free tobacco extract. However, it is unclear why CCD841 CoN cells appear to be more sensitive than HCT $116+$ hMLH1 and MRC-5 cells to the tobacco extract and why HCT $116+$ hMLH1, MRC-5 and CCD841 CoN cells arrested at different stages of the cell cycle after the treatment. Likely, the epithelial CCD841 CoN and the fibroblast MRC-5 cells exhibit cell type specific responses to the tobacco extract attributed to distinctive signaling pathways [21] and chemicals released from the cells [22]. Future studies such as system biology approaches should be considered to elucidate the molecular bases for the differential response among the cells to the nicotine-free tobacco extract.

\section{Conclusions}

The nicotine-free tobacco extract may serve as a chemoprevention agent that mitigates tumorigenesis at precancerous stages. Thus, the nicotine-free tobacco extract is of nutraceutical potential. Among the bioactive compounds present in tobacco leaves, nicotine appears to target cancer cells [15] while other components may play a role at precancerous stages. To sustain and encourage tobacco planting for applications other than cigarette production, it is of future interest to identify bioactive compounds in the nicotine-free tobacco extract and elucidate the signalling pathways against tumorigenesis.

\section{Acknowledgements}

This work was partially supported by the US Department of Agriculture (Grant No. 2006-34467-17102) and the leadership of The Honorable Steny H. Hoyer United States House of Representatives. Ying Yu is a recipient of the Chinese Top University Graduate Student Studying Abroad Award, China Scholarship Council.

\section{References}

1. Fantozzi P, Sensidoni A (1983) Protein extraction from tobacco leaves: technological, nutritional and agronomical aspects. In: Bodwell CE, Petit L (Eds.), Plant Protein for Human Food. W Junk Publishers New York 147-149.

2. Fu H, Machado PA, Hahm TS, Kratochvil RJ, Wei Cl, et al. (2010) Recovery of nicotine-free proteins from tobacco leaves using phosphate buffer system under controlled conditions. Bioresour Technol 101: 2034-2042.

3. Kawashima N, Wildman SG, Fraction I (1970) A model of the subunit structure of fraction 1 Protein. Annu Rev Plant Physiol 21: 325-358.

4. Chung HY, Lee HH, Kim KI, Hwang-Bo J, Park JH, et al. (2011) Expression of a recombinant chimeric protein of hepatitis A virus VP1-FC using a replicating vector based on Beet curly top virus in tobacco leaves and its immunogenicity in mice. Plant Cell Rep 30: 1513-1521.

5. Fu H, Pang S, Xue P, Yang J, Liu X, et al. (2011) High Levels of Expression of Fibroblast Growth Factor 21 in Transgenic Tobacco (Nicotiana benthamiana). Appl Biochem Biotechnol 165: 465-475.

6. Murkute AV, Sahu MS, Mali PY, Rangari VD (2010) Development and evaluation of formulations of microbial biotransformed extract of tobacco leaves for hair growth potential. Pharmacognosy Res 2: 300-303.

7. Waheed MT, Thönes N, Müller M, Hassan SW, Razavi NM, et al. (2011) Transplastomic expression of a modified human papillomavirus L1 protein leading to the assembly of capsomeres in tobacco: a step towards costeffective second-generation vaccines. Transgenic Res 20: 271-282.

8. Bartkova J, Horejsí Z, Koed K, Krämer A, Tort F, et al. (2005) DNA damage response as a candidate anti-cancer barrier in early human tumorigenesis. Nature 434: 864-870

9. Bartkova J, Rezaei N, Liontos M, Karakaidos P, Kletsas D, et al. (2006) Oncogene-induced senescence is part of the tumorigenesis barrier imposed by DNA damage checkpoints. Nature 444: 633-637.

10. Gorgoulis VG, Vassiliou LV, Karakaidos P, Zacharatos P, Kotsinas A, et al (2005) Activation of the DNA damage checkpoint and genomic instability in human precancerous lesions. Nature 434: 907-913.

11. Burma S, Chen BP, Murphy M, Kurimasa A, Chen DJ (2001) ATM phosphorylates histone $\mathrm{H} 2 \mathrm{AX}$ in response to DNA double-strand breaks. J Bio Chem 276: 42462-42467

12. Jiricny J (2006) The multifaceted mismatch-repair system. Nat Rev Mol Cell Biol 7: 335-346.

13. Kunkel TA, Erie DA (2005) DNA mismatch repair. Annu Rev Biochem 74: 681710.

14. Waters R (2006) Maintaining genome integrity. EMBO Rep 7: 377-381.

15. Elias ST, Diniz J, Almeida RS, Alvarenga N, Simeoni LA, et al. (2010) Cytotoxic effect of tobacco extracts on human oral squamous cell carcinoma cell-line. Oral Oncol 46: 869-873.

16. Qi Y, Schoene NW, Lartey FM, Cheng WH (2010) Selenium compounds activate ATM-dependent DNA damage response via the mismatch repair protein hMLH1 in colorectal cancer cells. J Biol Chem 285: 33010-33017.

17. Jacob S, Aguado M, Fallik D, Praz F (2001) The role of the DNA mismatch 
Citation: Yu Y, Soma PK, Lo YM, Wei CL, Cheng WH (2012) Effect of Nicotine-free Tobacco Extract on DNA Damage Responses in Cancerous and Non-cancerous Cells. J Carcinogene Mutagene S3:002. doi:10.4172/2157-2518.S3-002

Page 5 of 5

repair system in the cytotoxicity of the topoisomerase inhibitors camptothecin and etoposide to human colorectal cancer cells. Cancer Res 61: 6555-6562.

18. Park JW, Yoon JY, Kim YJ, Kyung SY, Lee SP, et al. (2010) Extracellular signal-regulated kinase (ERK) inhibition attenuates cigarette smoke extract (CSE) induced-death inducing signaling complex (DISC) formation in human lung fibroblasts (MRC-5) cells. J Toxicol Sci 35: 33-39.

19. Wu M, Kang MM, Schoene NW, Cheng WH (2010) Selenium Compounds Activate Early Barriers of Tumorigenesis. J Biol Chem 285: 12055-12062.

20. Chen RJ, Chang LW, Lin P, Wang YJ (2011) Epigenetic Effects and Molecular
Mechanisms of Tumorigenesis Induced by Cigarette Smoke: An Overview. J Oncol 2011: 654931.

21. Skinner J, Bounacer A, Bond JA, Haughton MF, deMicco C, et al. (2004) Opposing effects of mutant ras oncoprotein on human fibroblast and epithelial cell proliferation: implications for models of human tumorigenesis. Oncogene 23: 5994-5999.

22. Knight D (2001) Epithelium-fibroblast interactions in response to airway inflammation. Immunol Cell Biol 79: 160-164.

This article was originally published in a special issue, DNA damage/ repair: Mutagenesis : Carcinogenesis handled by Editor(s). Dr. Lubomir Manolov Stoilov, University: Institute of Genetics, Bulgaria; Dr. Kandace Jo Williams, University of Toledo College of Medicine, USA; Dr. Mu Wang, Indiana University School of Medicine, USA 